\title{
Western scrub-jays do not appear to attend to functionality in Aesop's Fable experiments
}

Corina J Logan, Brigit D Harvey, Barney A Schlinger, Michelle Rensel

Western scrub-jays are known for their highly discriminatory and flexible behaviors in a caching (food storing) context. However, it is unknown whether their cognitive abilities are restricted to a caching context. To explore this question, we tested scrub-jays in a noncaching context using the Aesop's Fable paradigm, where a partially filled tube of water contains a floating food reward and objects must be inserted to displace the water and bring the food within reach. We tested 4 birds, but only 2 learned to drop stones proficiently. Of these, 1 bird participated in 4/5 experiments and 1 in 2/5 experiments. Both birds passed 1 experiment, but without attending to the functional differences of the objects, and failed the other experiments. Scrub-jays were not motivated to participate in these experiments, suggesting that either this paradigm was ecologically irrelevant or perhaps their flexibility is restricted to a caching context. 
1 Western scrub-jays do not appear to attend to functionality in Aesop's Fable experiments

2 Corina Logan ${ }^{1 *} \sim$, Brigit Harvey ${ }^{2}$, Barney A. Schlinger ${ }^{2,3,4}$, Michelle Rensel ${ }^{2}$

3

$4{ }^{1}$ SAGE Center for the Study of the Mind, University of California Santa Barbara, Santa Barbara,

5 CA USA

$6 \quad{ }^{2}$ Department of Integrative Biology and Physiology, University of California Los Angeles, Los

7 Angeles, CA USA

$8{ }^{3}$ Department of Ecology and Evolutionary Biology, UCLA, Los Angeles, CA USA

$9{ }^{4}$ Laboratory of Neuroendocrinology, Brain Research Institute, UCLA, Los Angeles, CA USA

10 Current address: Department of Zoology, University of Cambridge, Downing Street,

11 Cambridge, CB2 3EJ, UK

12

$13 *$ Corresponding author:

14 Corina Logan

15 Department of Zoology, University of Cambridge, Downing Street, Cambridge, CB2 3EJ, UK 16 c1417@cam.ac.uk 


\section{ABSTRACT}

18 Western scrub-jays are known for their highly discriminatory and flexible behaviors in a caching

19 (food storing) context. However, it is unknown whether their cognitive abilities are restricted to a

20 caching context. To explore this question, we tested scrub-jays in a non-caching context using

21 the Aesop's Fable paradigm, where a partially filled tube of water contains a floating food

22 reward and objects must be inserted to displace the water and bring the food within reach. We

23 tested 4 birds, but only 2 learned to drop stones proficiently. Of these, 1 bird participated in 4/5

24 experiments and 1 in 2/5 experiments. Both birds passed 1 experiment, but without attending to

25 the functional differences of the objects, and failed the other experiments. Scrub-jays were not

26 motivated to participate in these experiments, suggesting that either this paradigm was

27 ecologically irrelevant or perhaps their flexibility is restricted to a caching context.

\section{INTRODUCTION}

30 Western scrub-jays (Aphelocoma californica; hereafter referred to as scrub-jays) are known for

their highly discriminatory and flexible behaviors in a caching (food storing) context. For example, scrub-jays prefer to recover perishable food items sooner than non-perishable items (Clayton et al. 2001), they plan what they want for breakfast the next morning (Raby et al. 2007), and scrub-jays with prior experience stealing other's caches use cache protection strategies (Dally et al. 2006, see review in Grodzinski \& Clayton 2010). However, it is unknown whether such abilities are restricted to a caching context - the context in which these abilities evolved

37 (Grodzinski \& Clayton 2010).

To begin to answer this question, we tested scrub-jays in a non-caching context using the

39 Aesop's Fable paradigm. In this paradigm, clear tubes that are partially filled with water contain 
40 a floating food reward that can only be reached by inserting objects into the tube to raise the

41 water. These experiments investigate how individuals solve problems by giving them objects or

42 tubes that vary in their functionality (Bird \& Emery 2009a, Taylor et al. 2011, Cheke et al. 2011,

43 Jelbert et al. 2014, Logan et al. 2014, Jelbert et al. 2015). If individuals choose the functional

44 option significantly more than the non-functional option, it indicates that they might have a

45 causal understanding of the properties of objects and substrates. Alternatively, they might have

46 an innate bias toward the more functional object or they might associate the movement of the

47 food in the tube (e.g., rising to the top of the tube with every object dropped in) with the

48 particular substrate or object type. To probe these explanations and understand how individuals

49 solve these tasks, particularly whether they use causal cognition, tasks are often presented where

50 the solution violates causal explanations and thus are counter-intuitive in this context. These tests

51 involve the presentation of an apparatus with a hidden mechanism such that individuals must rely

52 on arbitrary cues (e.g., color cues) to solve the problem because there are no causal cues to attend

53 to. Therefore, if an individual uses causal cues when solving water tube tasks, they should fail

54 the counter-intuitive experiments (Cheke et al. 2011, Jelbert et al. 2014, Logan et al. 2014).

55 Failure to learn to associate an arbitrary cue over the course of 20 trials in experiments that

56 function in such a way as to violate causal expectations is interpreted as evidence that individuals

57 rely to some degree on causal information to solve water tube tasks.

In all other corvid species tested (rooks, New Caledonian crows, and Eurasian jays) using

59 the Aesop's Fable paradigm, at least some individuals successfully solved the tasks (Table 1, see

60 Jelbert et al. 2015 for a full overview). These individuals were sensitive to the functional

61 properties of objects and substrates because they preferred the more functional option to gain a

62 food reward. Almost all individuals failed the counter-intuitive colored U-tube test, which 
63 suggests they might rely to some degree on causal cues to solve water tube tasks. The only non-

64 corvid bird tested so far, the great-tailed grackle (Quiscalus mexicanus), was also successful in

65 Aesop's Fable experiments and two individuals changed their preferences when circumstances

66 changed, indicating behavioral flexibility (Logan 2015a). Of these species, the Eurasian jay is the

67 only other caching specialist and it exhibited flexibility outside of a caching context (Brodin \&

68 Lundborg 2003, Pravosudov \& de Kort 2006). This leaves an open question of whether scrub-

69 jays can apply their flexibility outside of a caching context.

We gave scrub-jays five Aesop's Fable experiments that have been conducted on other

71 bird species to make their performance comparable. Although some species that have passed

72 these experiments make and use tools in the wild, non-tool using birds are also able to pass these

73 tests (Table 1). Therefore, these experiments should be within the capacity of the non-tool using

74 scrub-jays (Lefebvre et al. 2002). In Experiment 1 (Water vs. Sand), one tube was partially filled

75 with water and the other with sand; stones were available to solve the task by dropping them into

76 the water tube (Bird \& Emery 2009, Taylor et al. 2011, Jelbert et al. 2014, Logan et al. 2014).

77 Experiment 2 (Heavy vs. Light) consisted of one water tube with more functional heavy objects

78 and less functional light objects, while Experiment 3 (Heavy vs. Light Magic) was the same

79 except the heavy objects became non-functional because they stuck to a magnet while the light

80 objects became the functional option because they fell past the magnet (Logan 2015a).

81 Behavioral flexibility, the ability to quickly change preferences when the task changes, would be

82 demonstrated if individuals that preferred heavy objects or had no object preference in

83 Experiment 2 changed their preference to either no preference or to preferring light objects in

84 Experiment 3. 

colored apparatuses, each with a small tube containing food, but too small to insert stones, and a

87 large tube that could accommodate stones (Logan et al. 2014). One apparatus had a hidden 88 connector tube under the lid that connected the large and small tubes such that if a stone was 89 dropped in to the connected large tube, the water levels would rise in both the large and small 90 tubes. To succeed, the bird must associate the color of the connected apparatus or the movement 91 of the food with receiving a food reward to complete the task. This experiment was modified 92 from its previous version (in Logan et al. 2014): we made each apparatus more visually distinct 93 through expanding the color cues and shapes to include the whole apparatus and both tubes. 94 These changes should facilitate the perception that both tubes belonged to one apparatus rather 95 than being separate. Experiment 5 (Uncovered U-tube) was the same as Experiment 4 except all 96 color cues were removed and the connector tube exposed so the bird could see how the apparatus 97 worked (Logan et al. 2014). Additionally, the water in the large tubes was tinted with food 98 coloring such that when stones were dropped into the connected apparatus, water in the 99 connected small tube would change color, therefore allowing the mechanism (the connector 100 tube) to be even more visible. Because other bird species have succeeded at these tests regardless of whether they are a caching specialist or a tool user, we predict that scrub-jays will perform similarly. Specifically, we predict that they will prefer water-filled rather than sand-filled tubes (as in corvids), and

104 heavy rather than light objects and that they will change their preferences when the heavy objects 105 become non-functional (as in grackles). We also predict that they will not learn to associate color 106 with a reward in the colored U-tube experiment or attend to the exposed mechanism in the 107 uncovered U-tube experiment (similar to most corvids). If scrub-jays attend to the functional 
108 properties of objects and substrates and flexibly change their preferences when the task changes,

109 this would indicate that their highly discriminatory and flexible behavior generalizes to

110 conditions outside of the context in which their cognitive abilities evolved.

111

\section{METHODS}

\section{Animal Ethics}

114 This research was carried out in accordance with the University of California, Los Angeles'

115 (UCLA) Institutional Animal Care and Use Committee (protocol number 1995-026-63).

\section{Subjects}

118 Three wild adult male Western scrub-jays (Aphelocoma californica) were caught using Potter

119 traps baited with peanuts in southern California (July-August 2013), and one female nestling

120 (BB; an adult at the time of these experiments) was taken from the nest in the summer of 2012

121 and hand-raised (all captures were authorized under appropriate federal and state collecting

122 permits). Birds were sexed genetically (following Griffiths et al. 1998), and the validity of this

123 measure was confirmed via inspection of the gonads by Rensel and colleagues (2015). Moreover,

124 in Rensel et al. (2015), all four scrub-jays successfully participated in caching experiments, thus

125 indicating their acclimation to captivity. Before and after our experiments, scrub-jays were

126 housed socially with 2-4 birds per aviary (except for BB who was housed singly during a period

127 in which she behaved aggressively toward conspecifics). For the duration of our experiments,

128 scrub-jays were housed singly, in visual but not auditory isolation of other birds, in aviaries

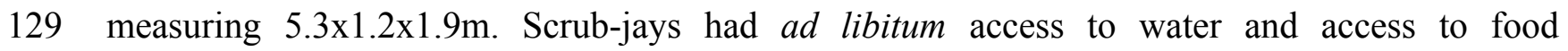

130 (Roudybush Daily Maintenance Diet, fruit, and mealworms) for a minimum of 15 hours every 
131 day. Non-testing food was removed before and during testing when testing occurred. Birds were

132 tested in two batches: BB and GG were tested from August 2014 to January 2015 (requiring 1-3

133 days per bird per experiment, spread out over the course of between 1-7 days), and PA and H

134 from June to November 2015.

\section{Experimental Set Up}

137 After placing birds in testing aviaries, they were first habituated to testing apparatuses and

138 stones. This was accomplished by feeding birds off of the apparatuses in which the relevant

139 openings were covered by tape so the birds could not discover how the apparatus worked. Once

140 birds readily approached and ate food off of an apparatus or stone, they were considered

141 habituated and the experiment began. If a bird needed to be re-habituated in the middle of an

142 experiment, the experiment was paused for this habituation to take place. For each experiment,

143 testing apparatuses were placed on a paper-covered table $(0.3 \times 1.1 \times 0.6 \mathrm{~m})$ inside the aviary with

144 perches placed above the table to allow easier access to the apparatuses. Testing lasted up to five

145 hours per day between 0700 and 1600. If testing occurred in the morning, food was removed

146 from the aviaries the night before (between 1800 and dusk). For afternoon test sessions, food was

147 removed at 0700 . Testing sessions lasted up to approximately 20 minutes. Trials ended if the bird

148 obtained the reward or did not interact with the task after 4 minutes, at which point the apparatus

149 was removed from the testing aviary for at least 10 minutes before resuming the session. If a bird

150 did not interact with the task after 2 minutes, bait (a small peanut piece) was placed on the table

151 equidistant between the tubes (if a two-tube experiment) or objects to encourage the bird to

152 participate. If the previous session ended with no participation in the task, the first trial of the

153 next session began with bait, thus a trial was baited up to 2 times. An experiment was ended 
154 before completion due to a lack of the bird's motivation if the bird did not interact with the

155 apparatus for 5 consecutive sessions over the course of multiple days. Water tubes were baited

156 with peanut pieces attached to cork using a tie wrap to allow the food to float (hereafter referred

157 to as peanut floats). Experiments $1-5$ consisted of 20 trials per bird per experiment. All

158 experiments were recorded with a Sony Handycam HD camera on a tripod.

160 Color Learning for Side Bias Prevention

161 To prevent side bias during the water tube experiments involving two tubes, scrub-jays were

162 required to learn to associate food with color, forcing them to attend to color rather than location

163 (as in Logan et al. 2014). A gold tube always contained food (small peanut pieces), while a silver

164 tube never did. One gold and one silver tube were placed on the table, one on the left and one on

165 the right (left side first, pseudorandomized for side) with the open ends of the tubes facing the

166 side walls such that birds could not see which tube contained the food. Birds were habituated to

167 the task using a blue tube (all tubes measured 50x50x67mm, outer diameter $=26 \mathrm{~mm}$, inner

168 diameter $=19 \mathrm{~mm}$ ) until they learned to search for food even if it was not visible. After

169 habituation, the color learning test began and scrub-jays got one choice per trial, marked as the

170 first tube they look into, and proficiency was reached when an individual chose the gold tube at

171 least 17 out of the most recent 20 trials (having achieved at least 8 out of 10 on each set of 10

172 contributing to the passing score). Pseudorandomization consisted of alternating sides for the

173 first two trials and then allowing each tube to remain on the same side for a maximum of two

174 consecutive trials.

175 Between 20 and 80 trials were required for three birds to reach proficiency (Table 2),

176 similar to grackles (Logan 2015a), Darwin's finches (Tebbich et al. 2010), and pigeons (Lissek 
177 et al. 2002), and faster than pinyon jays, Clark's nutcrackers, and previously tested Western

178 scrub-jays (Bond et al. 2007). GG did not complete this training due to his lack of willingness to

179 come to the table to participate in the task. During two-tube water tube experiments

180 (Experiments 1, 4, and 5), a side bias was considered to have developed if a bird approached the

181 same side three or more times. At this point, the experiment was suspended and the subject was

182 given the color test. If they chose gold at least 8 out of 10 trials, the experiment resumed.

183 However, if they no longer had a color preference, they were tested until they chose gold at least

18417 out of the most recent 20 trials (per the criteria above), and then the experiment resumed.

185 Color trials were given to BB after trial 18 in the Colored U-tube experiment and after trial 14 in

186 the Uncovered U-tube experiment. GG did not develop side biases.

187

188 Stone Dropping Training

189 Birds were trained to lift stones off of the testing table, carry them to the perch, and drop them

190 down the tube of an apparatus with a collapsible platform. The apparatus was a clear cast acrylic

191 box $(185 \times 110 \times 85 \mathrm{~mm})$ with a $90 \mathrm{~mm}$ tube (outer diameter: $51 \mathrm{~mm}$, inner diameter: $43 \mathrm{~mm}$ ) on top

192 of the box and a platform inside that was held up by a magnet (Figure 1A; as in Bird \& Emery

193 2009). Magnetic contact was broken upon impact from the stone dropped into the tube, allowing

194 the platform to fall down and release food onto the table. Birds were first encouraged to

195 accidentally push the stone into the tube by placing a small piece of peanut under the stone

196 balanced on the edge of the rim. They then progressed to picking up and dropping the stone into

197 the tube from anywhere on the table. Birds accessed the top of the tube by standing on a perch

198 placed near the top of the tube rather than by standing on the ground because they were more

199 willing to participate in this context. The configuration (e.g., standing on a perch or the ground) 
200 should not have influenced the bird's perception of the task because, in both scenarios, their head

201 was always over the tube when the object was dropped in and birds could move their heads to

202 look at the outside of the tube. Proficient stone drops were defined as those in which the bird

203 picked up the stone from the table and directly dropped it into the tube. Once proficiency was

204 reached, 30 more trials were conducted to ensure their expertise on the task. BB and GG required

20576 and 255 trials to pass this training, respectively, while PA and $\mathrm{H}$ never passed (we stopped

206 their training at 536 and 507 trials, respectively; Table 2).

207

208 Multi-stone Dropping Training

209 After reaching proficiency on stone dropping training, birds received multi-stone dropping

210 training to learn that solving a task might require dropping more than one object into the tube.

211 The multi-stone apparatus was similar to the stone dropping training apparatus, but had a larger

212 box (box: 200x180x150mm; tube: $95 \mathrm{~mm}$ tall, $50 \mathrm{~mm}$ outer diameter, $44 \mathrm{~mm}$ inner diameter;

213 Figure 1B; design in Logan et al. 2014) and the platform was balanced on a circular rod rather

214 than being held up by a magnet. Counterweights placed at the rear of the platform ensured that 2-

2154 stones needed to drop down the tube and then slide down a ramp to land on the front of the

216 platform before the platform would fall open, thus releasing the food. Individuals passed this

217 training once they successfully solved 10 consecutive trials. BB and GG were immediately

218 proficient, thus they completed all 10 trials proficiently.

219

220 Reachable Distance

221 After multi-stone dropping training, the height at which a bird could reach the food in the tube

222 was determined in advance to establish how high to set the water level in the experiments. This 
223 was necessary so that the food would be out of reach and require the desired number of objects to

224 bring it within reach. The reachable distance was the distance from the bottom of the tube to the

225 top of the food, which sat on top of a plastic sandwich bag stuffed with cotton in a standard tube

226 used in the water experiments (a clear cast acrylic tube measuring 170mm tall, 50mm outer

227 diameter, 43mm inner diameter and attached using super glue to a clear cast acrylic base

228 measuring 300x300x3mm). Birds were allowed to access the food (peanut floats), initially well

229 within reach, and then the distance was decreased until it was out of reach.

230

231 Experiment 1: Water vs. Sand

232 This experiment consisted of two standard tubes: one partially filled with sand and the other with

233 water to the same height in each tube, to determine whether birds preferred to drop stones into

234 the functional water tube rather than the non-functional sand tube (Figure 2; similar to Logan et

235 al. 2014). First, birds were given a 10-trial training period in which any initial tube preferences

236 were discouraged by heavily baiting the non-preferred tube. Tubes contained water and sand

237 (and were pseudorandomized for side), but no floating food. The tops of the tubes were taped

238 over and bait (peanut pieces) was placed on top and at the base of each tube. The tube the bird

239 ate from first was recorded to determine whether a preference emerged. After these training

240 trials, the experiment began and the sand and water tubes continued to be pseudorandomized for

241 side. Four stones (weighing 14-21g and displacing 6-8mm water) were located between the two

242 apparatuses: two on the base of one apparatus and two on the base of the other apparatus, and 243 each bird experienced 20 trials.

\section{Experiment 2: Heavy vs. Light}


246 One standard water tube was given with 8 objects: 4 heavy (a steel rod encased in fimo clay,

247 each weighing $10 \mathrm{~g}$ and displacing 2-3mm of water) and 4 light (black plastic tube partially filled

248 with fimo clay, each weighing $2 \mathrm{~g}$ and displacing 1-1.5mm water; Figure 3A; see Logan 2015a).

249 Heavy and light objects were $21-24 \mathrm{~mm}$ in length and $8 \mathrm{~mm}$ in diameter. Both objects sank,

250 making them both functional, however heavy objects had a larger volume $\left(1056-1207 \mathrm{~mm}^{3}\right)$ than

251 light objects (approximately $500 \mathrm{~mm}^{3}$ ). Therefore, heavy objects displaced more water and were

252 more functional. Volume differences were created by making one end of the inside of the tube

253 hollow for the light objects. First, birds were given a 3-trial object training period without a

254 water tube in which any initial object preferences were discouraged by placing relatively more

255 bait (peanut pieces) on the non-preferred object. A heavy and a light object were placed next to

256 each other on the table (pseudorandomized for location) and bait was placed underneath and on

257 top of both objects. The object the bird ate from first was recorded to determine whether a

258 preference emerged, and the trial ended when the bird had interacted with both objects. After

259 these object training trials, the 20-trial experiment began and pairs of heavy and light objects

260 were pseudorandomized for location.

261

262 Experiment 3: Heavy vs. Light Magic

263 This experiment was the same as Experiment 2, except here the heavy objects became non-

264 functional to determine whether birds could discriminate between the functional properties of the

265 objects and change their preference from the previous experiment. A magnet was attached to the

266 inside of the tube above the water level so that the heavy (metal) objects became non-functional

267 (they stuck to the magnet if inserted into the tube), thus making the light (non-metal) objects the

268 only functional option because they could fall past the magnet and into the water (Figure 3B). 
269 Three heavy and 3 light objects were placed in pseudorandomized pairs at the base of the tube

270 because 4 heavy objects would not fit on the magnet. Each bird was given 20 trials.

271

272 Experiment 4: Colored U-tube

273 This experiment consisted of two apparatuses made of clear cast acrylic, each containing a

274 standard tube and a small-diameter tube (small tube outer diameter $=25.4 \mathrm{~mm}$, inner

275 diameter $=19 \mathrm{~mm}$ ) $25 \mathrm{~mm}$ apart, with $160 \mathrm{~mm}$ of tube above and $90 \mathrm{~mm}$ below a clear cast acrylic

276 lid $(300 \times 400 \times 3 \mathrm{~mm})$ on a wooden box (Figure $4 \mathrm{~A})$. The small tubes contained out of reach

277 peanut floats (the reachable distance for each bird was obtained for the small tube prior to

278 beginning the experiment), but were too small for stone insertion. On one apparatus, a tube under

279 the lid connected the two water tubes such that inserting the stone into the standard tube resulted

280 in the food rising in the small tube. The connected apparatus was indicated by a particular color

281 (counterbalanced across birds) and was pseudorandomized for side. The apparatuses were the

282 same as in Logan et al. (2014) with modifications to make the two tubes on each apparatus

283 appear as part of the same apparatus and to distinguish the two apparatuses from each other.

284 Instead of both apparatuses having a white paper background with differently colored shapes at

285 the base of the standard tube, here each apparatus had a distinct background color (blue or

286 brown). On top of these backgrounds, each apparatus had a different color and shape (pink

287 triangle or yellow square) that extended around the base of the two tubes to further unify the

288 tubes of each apparatus by making them appear more as a single unit, instead of only extending

289 around the base of the standard tube. The tops of each apparatus' tubes were marked with

290 electrical tape identical to the colored shape at the base (pink or yellow). One white strip of

291 electrical tape was placed on each apparatus to indicate that these are the same apparatuses in the 
292 next experiment. Any initial apparatus preferences were discouraged by heavily baiting the non-

293 preferred apparatus over the course of 10 trials as in Experiment 1. Four stones were placed

294 between the apparatuses as in Experiment 1 and 20 trials were given to each bird.

295

296 Experiment 5: Uncovered U-tube

297 This experiment was the same as Experiment 4 except all paper and color cues were removed 298 and the boxes around the bases were removed on both apparatuses, thus exposing the connector 299 tube under the lid of the connected apparatus (Figure 4B). During the experiment, 20-30 drops of 300 red (for pink) or yellow food coloring (the same as the colored paper and tape on the connected

301 apparatus in Experiment 4) were placed into each wide tube such that when a stone was dropped

302 into the connected apparatus, the flow of tint from the standard to the small tube would show the 303 water flow through the connector tube. Note that the unconnected apparatus had alternate dye 304 patterns during BBs first 3 trials before settling on this methodology: there was red dye in trials 1 305 and 2, and no dye in trial 3.

306

307 Statistical Analyses

308 Binomial tests were carried out in R v3.2.1 (R Core Team 2015), and, when there were multiple 309 p-values per experiment, they were corrected using the Bonferroni-Holm method.

\section{RESULTS}

312 All choices per trial per bird are shown in Table 2 and a video showing examples of the 313 experiments is available online at: https://youtu.be/RCNENBwsbA8. During the pre-experiment 
314 trials to control for preferences, there was no preference across birds in their first trial for one

315 object/tube or the other (see data at KNB; Logan 2015)

316

317 Experiment 1: Water vs. Sand

318 GG had no preference for which tube to drop the stones into (Table 3). BB did not complete this

319 experiment. Her motivation to participate declined, possibly because she received few food 320 rewards (she primarily chose the sand tube). To prevent her from giving up on dropping objects

321 down tubes entirely, she was given alternating sessions with either a single water tube or the

322 multiple stone dropping apparatus and stones for four days until she began regularly interacting 323 with the water tube again.

324

325

\section{Experiment 2: Heavy vs. Light}

326

BB and GG consistently successfully obtained the food using both heavy and light objects without a preference for the more functional heavy objects (Table 3).

\section{Experiment 3: Heavy vs. Light Magic}

BB had no preference for heavy or light objects, though it appeared that she was developing a preference for light objects near the end of her experiment so it is possible that the preference would have been significant given more trials (Table 3). GG stopped participating in experiments at this time at first because of his neophobic reaction to the magnet, but even after a successful magnet habituation period, his motivation for participating in tests did not recover.

\section{Experiment 4: Colored U-tube}


337 BB had no preference for dropping stones into the standard tube on the brown apparatus, which

338 indicated the connected apparatus (Table 3).

339

340 Experiment 5: Uncovered U-tube

341 BB had no preference for dropping stones into the connected apparatus (Table 3).

342

343 DISCUSSION

344 Two scrub-jays successfully obtained the food in the Heavy vs. Light experiment because both

345 objects were functional, however, contrary to predictions, no scrub-jays attended to the

346 functional differences between objects or tubes or changed their preference when the task

347 changed. In every other species tested so far, including a caching specialist (Eurasian jay), at

348 least some individuals attended to the functional differences between objects and/or substrates,

349 thus making the scrub-jays the first species tested to fail to demonstrate such attention to 350 function (Bird \& Emery 2009a, Cheke et al. 2011, Taylor et al. 2011, Jelbert et al. 2014, Logan

351 et al. 2014). While it appeared that BB was learning to prefer light objects in Heavy vs. Light

352 Magic, she did not learn to significantly prefer this object type within the 20 trials that are

353 standard for these experiments. Consistent with predictions, scrub-jays performed similarly to

354 most previously tested corvids and failed the U-tube tests. Failure on the Colored U-tube task

355 could indicate that a degree of causal cognition is used to solve this problem because attention to

356 causal cues and expectations about causal relationships could inhibit learning to associate

357 arbitrary cues with a food reward (Cheke et al. 2011, Jelbert et al. 2014, Logan et al. 2014). The

358 color and water flow modifications to the Colored U-tube and Uncovered U-tube experiments

359 did not appear to facilitate learning to prefer the connected apparatus. 

solve. In all species previously tested, except grackles, the heavy objects sank and the light

362 objects floated, therefore functionality was dichotomous (Bird \& Emery 2009a, Cheke et al.

363 2011, Taylor et al. 2011, Jelbert et al. 2014, Logan et al. 2014, Logan 2015a). In the grackle

364 (Logan 2015a) and scrub-jay experiments, both items were functional, but heavy were

365 approximately twice as effective as light objects. This modification allowed a follow up 366 experiment (Heavy vs. Light Magic) within the Aesop's Fable to test behavioral flexibility.

367 However, this modification had other consequences. First, it made functional discriminations

368 between heavy and light objects more difficult: there was a smaller difference in the functionality 369 of the objects because both objects sank, thus birds were not forced to discriminate between 370 objects to obtain the food. The follow up experiment, Heavy vs. Light Magic, was designed to 371 test attention to the functionality of the objects, and in this case, the one scrub-jay who 372 participated in both of these experiments exhibited no preference in either test. Second, the 373 functionality of the light object was disassociated from its weight because the smaller volume is 374 what caused it to displace less water. This means that birds could solve the task by associating 375 light objects with receiving food due volume differences or by using the methods proposed for 376 other species if they bind the association of volume with weight. This potentially made the task 377 more difficult. Additionally, the Heavy vs. Light Magic experiment was more difficult than other 378 experiments because heavy items that were dropped into the tube stuck to the magnet and 379 blocked access to the floating food reward. Therefore, a bird should inhibit dropping any heavy 380 objects and switch to only dropping light objects into the tube to more easily obtain the food, 381 thus making this task particularly difficult. Perhaps scrub-jays would have passed the easier 382 version (sinking vs. floating) of this experiment if they were given the opportunity. 
384 to examine an alternative explanation for how individuals solve Aesop's Fable tests: the object-

385 bias hypothesis (Logan et al. 2014, Jelbert et al. 2015). In previous Heavy vs. Light experiments

386 where heavy items sank and light items floated, all individuals preferred the heavy items. This

387 could indicate that they attended to the functional differences of the objects or that they had an

388 innate bias toward the heavy objects perhaps because they were more similar to objects in the

389 wild such as stones. Since both scrub-jays tested did not have an object preference in the

390 modified design, this suggests that object biases might not drive their choices. That scrub-

391 jays can learn to drop stones down tubes and successfully obtain a food reward in the Heavy vs.

392 Light experiment is further confirmation that non-tool using species are capable of this tool use

393 task (Table 1). The two scrub-jays that became proficient at stone dropping required a similar

394 amount of training as required by grackles (6 grackles learned in 135-362 trials and 2 grackles

395 never learned; Logan 2015a) and New Caledonian crows (6 crows learned in 1-116 trials and

396 others never became proficient, C.J. Logan unpublished data). Using the same platform

397 apparatus, Eurasian jays and rooks needed far less training to learn the task (4 Eurasian jays

398 learned in 11-33 trials and 1 never became proficient, Cheke et al. 2011; whereas all 4 rooks

399 learned in 5 trials, Bird \& Emery 2009b). Two out of 4 scrub-jays never became proficient at

400 stone dropping, and thus did not participate in stone dropping experiments, and both scrub-jays

401 that participated in experiments did not participate in every experiment. It appeared that their

402 lack of motivation for participating in these kinds of tasks slowed their learning and could have

403 caused them to give up; alternatively they could have lacked motivation due to cognitive

404 limitations preventing them from solving the tasks. The exception was BB who showed more

405 motivation than the others and participated in more experiments, perhaps due to her being the 
406 only hand-raised jay in this group - a developmental experience that has been shown to improve

407 cognitive performance in other species (see Thornton \& Lukas 2012).

408

409 LIMITATIONS AND FUTURE DIRECTIONS

410 The scrub-jays' lack of motivation combined with their lack of a preference for the functional

411 options suggests that either the Aesop's Fable paradigm is too ecologically irrelevant for this

412 species or that their highly discriminatory and flexible behaviors do not transfer to a non-caching

413 context. Alternatively, it is possible that this species is capable of such discriminations: perhaps

414 the individuals in our small sample were not discriminatory but others might be. While other

415 studies using Aesop's Fable also had small sample sizes, at least 2 individuals from each study

416 made some functional discriminations. For example, in the Heavy vs. Light experiment, 4

417 grackles preferred heavy objects and 2 had no preference - the latter 2 grackles performing

418 similarly to the 2 scrub-jays. That we were only able to test 2 scrub-jays (and usually only 1 per

419 experiment) opens the possibility that we did not capture the range of individual variation

420 possible for this species in these experiments. Future studies using different non-caching

421 paradigms are needed to determine whether scrub-jays' cognitive abilities transfer to non422 caching contexts.

423

424 ACKNOWLEDGEMENTS

425 We thank Rick Klufas in the UCLA Bioshop; Joe Jablonski at the UCSB workshop; Russ Revlin

426 for his idea to tint the water in the U-tube experiment; Alison Greggor for her suggestion to use

427 the tint to indicate water flow; Rachael Shaw for her idea to use white tape as an indicator of U- 
428 tube apparatus continuity; and Sarah Jelbert, Zoe Johnson-Ulrich, and an anonymous reviewer

429 for helpful feedback on a previous draft of this manuscript.

430

431 DATA DEPOSITION

432 Data are available at the KNB Data Repository:

433 https://knb.ecoinformatics.org/\#view/corina_logan.20.3 (Logan 2015b).

435 SUPPLEMENTAL INFORMATION

436 A video showing examples of the experiments is available online at:

437 https://youtu.be/RCNENBwsbA8.

438

439

\section{REFERENCES}

440

441

442

443

444

445

446

447

448

Bird CD, Emery NJ. 2009a. Rooks use stones to raise the water level to reach a floating worm. Current Biology 19:1410-1414 DOI 10.1016/j.cub.2009.07.033.

Bird CD, Emery NJ. 2009b. Insightful problem solving and creative tool modification by captive nontool-using rooks. Proceedings of the National Academy of Sciences 106:10370-10375 DOI 10.1073/pnas.0901008106.

Bond AB, Kamil AC, Balda RP. 2007. Serial reversal learning and the evolution of behavioral flexibility in three species of North American corvids (Gymnorhinus cyanocephalus, Nucifraga columbiana, Aphelocoma californica). Journal of Comparative Psychology 121:372-379 DOI 10. 1037/0735-7036.121.4.372. 
449 Brodin A, Lundborg K. 2003. Is hippocampal volume affected by specialization for 450 food hoarding in birds? Proceedings of the Royal Society B 270:1555-1563 DOI 10.1098/rspb.2003.2413.

452 Cheke LG, Bird CD, Clayton NS. 2011. Tool-use and instrumental learning in the Eurasian jay (Garrulus glandarius). Animal Cognition 14:441-455 DOI

455

456

457

458

460

461

462

463

464

465

466

467

468

469

470

471 10.1007/s 10071-011-0379-4.

Clayton NS, Yu KS, Dickinson A. 2001. Scrub jays (Aphelocoma coerulescens) form integrated memories of the multiple features of caching episodes. Journal of Experimental Psychology: Animal Behavior Processes 27:17-29 DOI 10.1037//0097-7403.27.1.17.

Dally JM, Emery NJ, Clayton NS. 2006. Food-caching western scrub-jays keep track of who was watching when. Science 312:1662-1665 DOI 10.1126/science.1126539.

Griffiths R, Double MC, Orr K, Dawson RJG. 1998. A DNA test to sex most birds. Molecular Ecology 7:1071-1075.

Grodzinski U, Clayton NS. 2010. Problems faced by food-caching corvids and the evolution of cognitive solutions. Philosophical Transactions of the Royal Society of London B 365:977-987.

Hunt GR. 2000a. Human-like, population-level specialization in the manufacture of pandanus tools by New Caledonian crows Corvus moneduloides. Proceedings of the Royal Society of London B 267:403-413 DOI 10.1098/rspb.2000.1015.

Hunt GR. 2000b. Tool use by the New Caledonian crow Corvus moneduloides to obtain Cerambycidae from dead wood. Emu North Melbourne 100:109-114 DOI 10.1071/MU9852. 
472 Jelbert SA, Taylor AH, Cheke LG, Clayton NS, Gray, RD. 2014. Using the Aesop's

473 fable paradigm to investigate causal understanding of water displacement by New

$474 \quad$ Caledonian crows. PLoS ONE 9:e92895 DOI 10.1371/journal.pone.0092895.

475 Jelbert SA, Taylor AH, Gray RD. 2015. Investigating animal cognition with the

476 Aesop's Fable paradigm: Current understanding and future directions.

$477 \quad$ Communicative \& Integrative Biology 8:e1035846 DOI

478

$10.1080 / 19420889.2015 .1035846$.

479

480

481

482

483

484

485

486

487

488

489

490

491

492

Kenward B, Rutz C, Weir AA, Kacelnik A. 2006. Development of tool use in New Caledonian crows: inherited action patterns and social influences. Animal Behaviour 72:1329-1343 DOI 10.1016/j.anbehav.2006.04.007.

Lefebvre L, Nicolakakis N, Boire D. 2002. Tools and brains in birds. Behaviour, 139:939-973 DOI 10.1163/156853902320387918.

Lissek S, Diekamp B, Gunturkun O. 2002. Impaired learning of a colour reversal task after NMDA receptor blockade in the pigeon (Columba livia) associative forebrain (Neostriatum Caudolaterale). Behavioral Neuroscience 116:523-529 DOI 10.1037//0735-7044.116.4.523.

Logan CJ, Jelbert SA, Breen AJ, Gray RD, Taylor AH. 2014. Modifications to the Aesop's Fable paradigm change performances in New Caledonian crows. PLoS ONE 9:e103049 DOI 10.1371/journal.pone.0103049.

Logan CJ. 2015a. Innovation does not indicate behavioral flexibility in great-tailed grackles. bioRxiv. doi: http://dx.doi.org/10.1101/027706. 
493 Logan CJ. 2015b. Western scrub-jay water tube experiments, Los Angeles, CA USA

494 2014-2015. The Knowledge Network for Biocomplexity (KNB). DOI

495

496

497

498

499

500

501

502

503

504

R Core Team. 2015. $R$ : A language and environment for statistical computing. Vienna: really an underdog among food-caching corvids when it comes to hippocampal volume and food caching propensity? Brain, Behavior and Evolution 67:1-9 DOI $10.1159 / 000088855$. R Foundation for Statistical Computing. Available at https://www.R-project.org (accessed 31 October 2015).

Raby CR, Alexis DM, Dickinson A, Clayton NS. 2007. Planning for the future by western scrub-jays. Nature 445:919-921 DOI 10.1038/nature05575.

Rensel MA, Ellis JM, Harvey B, Schlinger BA. 2015. Sex, estradiol, and spatial memory in a food-caching corvid. Hormones and Behavior 75:45-54 DOI 10.1016/j.yhbeh.2015.07.022.

Skutch AF. 1954. Life histories of Central American birds: families Fringillidae, Thraupidae, Icteridae, Parulidae and Coerebidae (Vol. 31). Berkeley, California, USA: Cooper Ornithological Society.

Taylor AH, Elliffe DM, Hunt GR, Emery NJ, Clayton NS, Gray RD. 2011. New Caledonian crows learn the functional properties of novel tool types. PLOS ONE 6:e26887 DOI 10.1371/journal.pone.0026887. 
514 Tebbich S, Sterelny K, Teschke I. 2010. The tale of the finch: adaptive radiation and

515 behavioural flexibility. Philosophical Transactions of the Royal Society of London

$516 \quad B$ 365:1099-1109.

517 Thornton A, Lukas D. 2012. Individual variation in cognitive performance:

518 developmental and evolutionary perspectives. Philosophical Transactions of the

$519 \quad$ Royal Society B 367:2773-2783 DOI 10.1098/rstb.2012.0214. 
1

Single stone dropping apparatus (A) and multi-stone dropping apparatus (B).

Photo credit: Brigit Harvey.

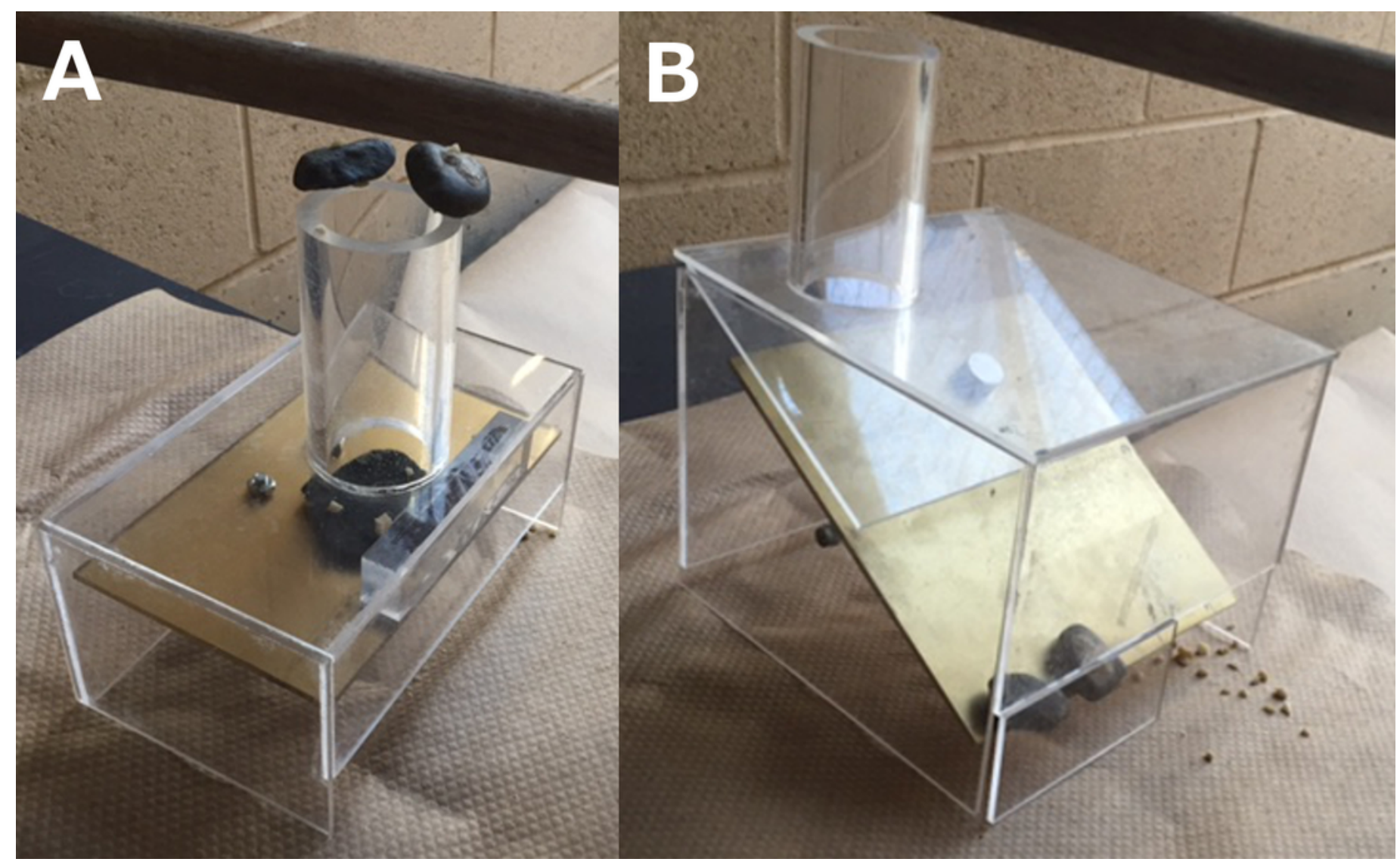


2

Water vs. sand experiment

Birds were given stones and could choose to drop them into the water-filled (functional) or sand-filled (non-functional) tube. Photo credit: Brigit Harvey.

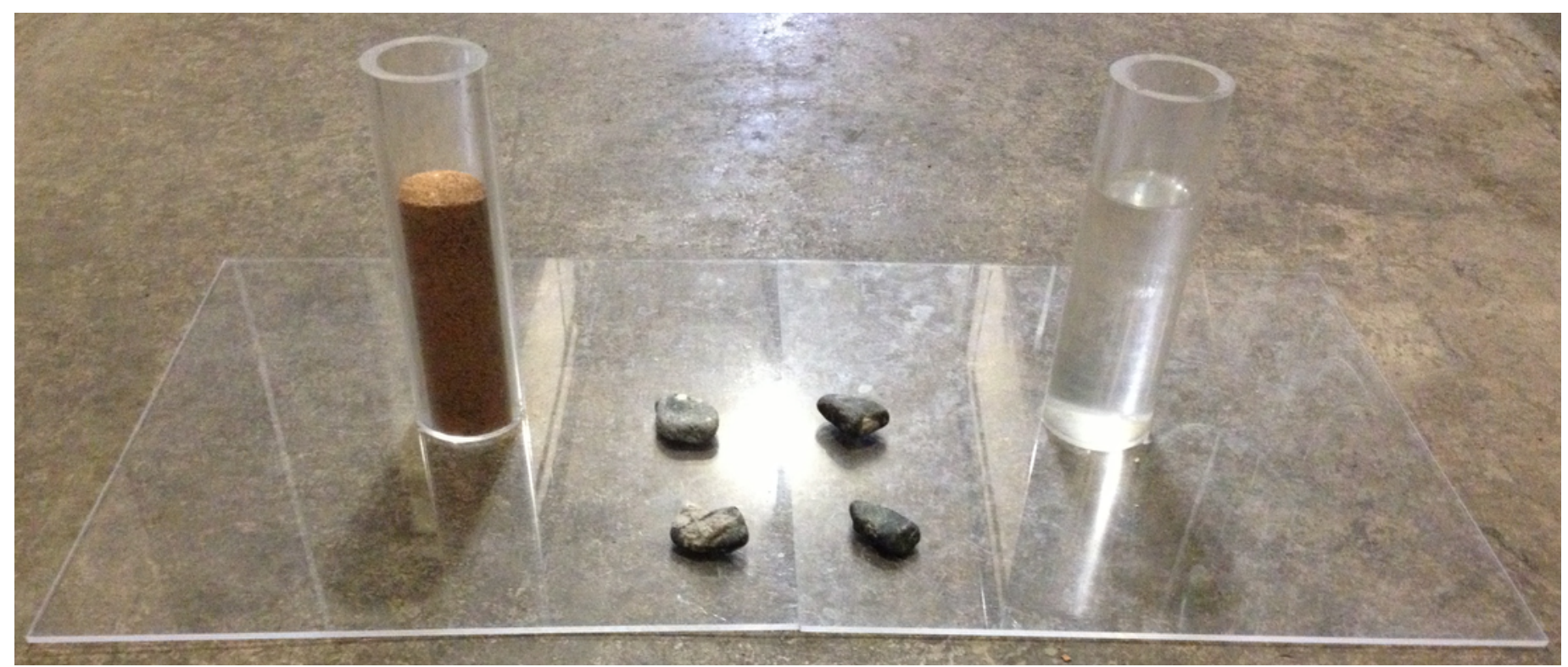


3

Heavy vs. Light (A) and Heavy vs. Light Magic (B) experiments.

Birds could drop heavy (more functional) and light (less functional) objects into the water tube (A). They were then given a follow up experiment where the heavy objects became nonfunctional because they stuck to a magnet placed on the tube above the water (notice the heavy object stuck to the magnet), thus making the light objects the only functional option (B). Photo credit: Brigit Harvey.

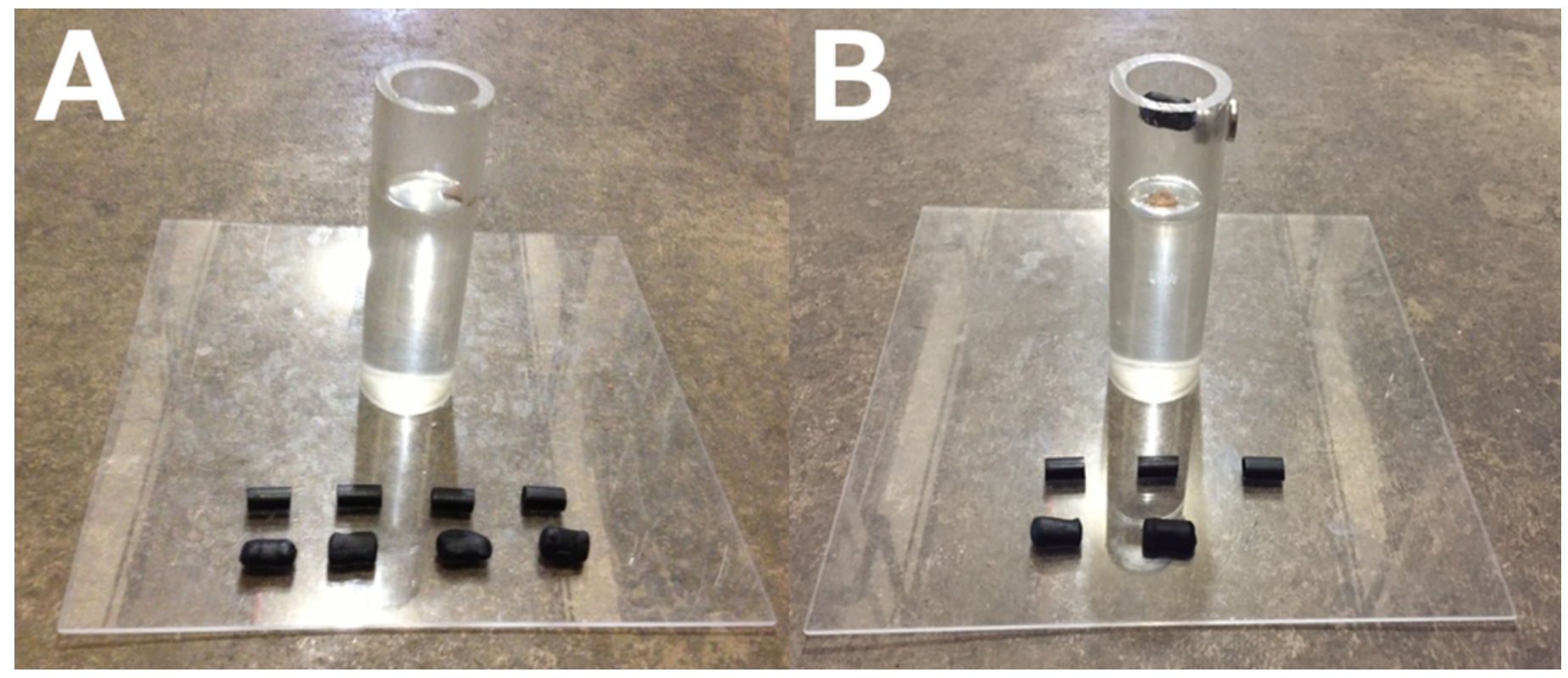


4

Colored U-tube (A) and Uncovered U-tube (B) experiments.

Birds were given stones that they could drop into the tube of the color that indicated the connected (functional) apparatus or the unconnected (non-functional) apparatus (A). In a follow up experiment, the connector tube was visible and birds could choose to drop stones into the connected (functional) or unconnected (non-functional) apparatuses (B). The connector tube is visible on the apparatus on the right in (B). Photo credit: Brigit Harvey.

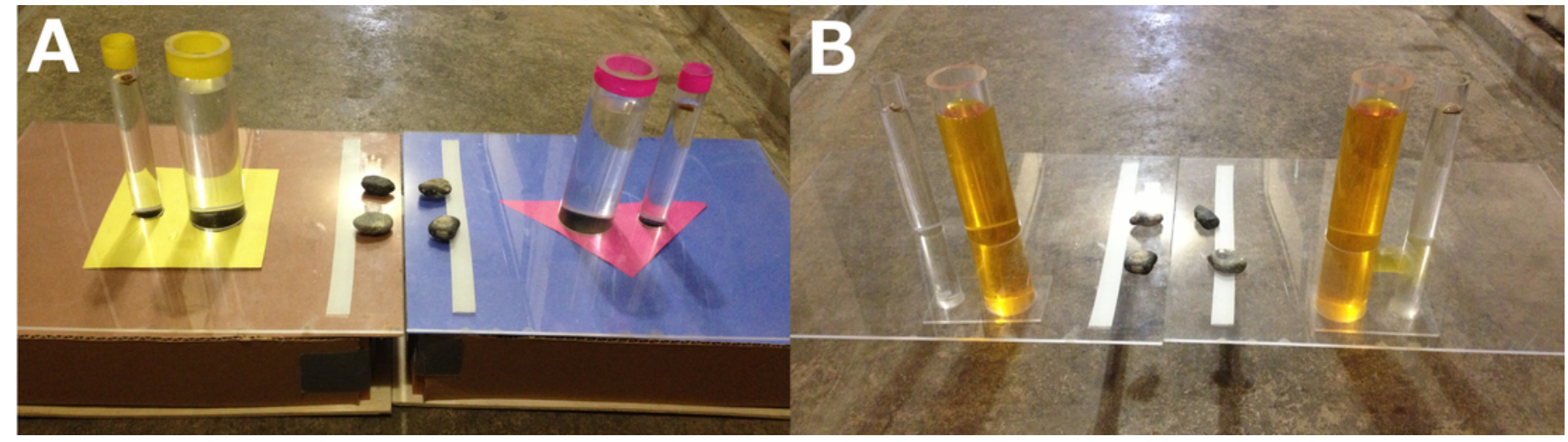




\section{Table $\mathbf{1}$ (on next page)}

Summary of results from previous Aesop's Fable experiments

A summary of the main results from previous tests on birds with varying degrees of caching specialization and tool using abilities. $\mathrm{n}=$ the total number of birds that began stone dropping training, $\mathrm{n}$ stone droppers $=$ the total number of birds that passed stone dropping training. For a more detailed summary see Jelbert et al. 2015. 


\begin{tabular}{|c|c|c|c|c|c|c|c|c|c|c|c|c|}
\hline Bird Species & Cacher? & $\begin{array}{l}\text { Tool } \\
\text { user? }\end{array}$ & $\mathbf{n}$ & $\begin{array}{l}\text { n stone } \\
\text { droppers }\end{array}$ & Water Tube & Experiments & & & & & & Citation \\
\hline $\begin{array}{l}\text { Rook } \\
\text { (Corvus } \\
\text { frugilegus) }\end{array}$ & $\begin{array}{l}\text { Non- } \\
\text { specialist }^{\mathrm{a}}\end{array}$ & $\mathrm{No}^{\mathrm{d}}$ & 4 & 4 & $\begin{array}{l}4 \text { used just } \\
\text { enough } \\
\text { stones to } \\
\text { reach the } \\
\text { food }\end{array}$ & $\begin{array}{l}3 \text { preferred } \\
\text { large rather } \\
\text { than small } \\
\text { stones }\end{array}$ & $\begin{array}{l}3 \text { preferred } \\
\text { water over } \\
\text { sawdust } \\
\text { tube }\end{array}$ & & & & & $\begin{array}{l}\text { Bird \& } \\
\text { Emery } \\
\text { 2009a }\end{array}$ \\
\hline $\begin{array}{l}\text { Eurasian jay } \\
\text { (Garrulus } \\
\text { glandarius) }\end{array}$ & Specialist $^{\mathrm{a}}$ & $\mathrm{No}^{\mathrm{e}}$ & 5 & 4 & $\begin{array}{l}2 \text { preferred } \\
\text { baited over } \\
\text { unbaited tube }\end{array}$ & $\begin{array}{l}2 \text { preferred } \\
\text { sinking over } \\
\text { floating objects }\end{array}$ & $\begin{array}{l}2 \text { preferred } \\
\text { liquid over } \\
\text { solid or } \\
\text { empty tube }\end{array}$ & $\begin{array}{l}0 \text { preferred } \\
\text { connected } \\
\text { apparatus } \\
\text { when } \\
\text { mechanism } \\
\text { was hidden }\end{array}$ & & & & $\begin{array}{l}\text { Cheke et } \\
\text { al. } 2011\end{array}$ \\
\hline $\begin{array}{l}\text { New Caledonian } \\
\text { crow (Corvus } \\
\text { moneduloides) }\end{array}$ & Likelyb & Yes $^{b}$ & 5 & 4 & $\begin{array}{l}4 \text { used just } \\
\text { enough } \\
\text { stones to } \\
\text { reach the } \\
\text { food }\end{array}$ & $\begin{array}{l}\text { The group } \\
\text { preferred large } \\
\text { rather than } \\
\text { small stones }\end{array}$ & $\begin{array}{l}\text { The group } \\
\text { preferred } \\
\text { liquid over } \\
\text { solid or } \\
\text { empty tube }\end{array}$ & $\begin{array}{l}\text { The group } \\
\text { preferred } \\
\text { heavy over } \\
\text { light objects }\end{array}$ & & & & $\begin{array}{l}\text { Taylor et } \\
\text { al. } 2011\end{array}$ \\
\hline “" & & & 6 & 6 & $\begin{array}{l}5 \text { preferred } \\
\text { water over } \\
\text { sand tube }\end{array}$ & $\begin{array}{l}6 \text { preferred } \\
\text { sinking over } \\
\text { floating objects }\end{array}$ & $\begin{array}{l}5 \text { preferred } \\
\text { solid over } \\
\text { hollow } \\
\text { objects }\end{array}$ & $\begin{array}{l}0 \text { preferred } \\
\text { narrow } \\
\text { over wide } \\
\text { tube }\end{array}$ & $\begin{array}{l}4 \\
\text { preferred } \\
\text { wide over } \\
\text { narrow } \\
\text { tube }\end{array}$ & $\begin{array}{l}0 \text { preferred } \\
\text { connected } \\
\text { apparatus } \\
\text { when } \\
\text { mechanism } \\
\text { was hidden }\end{array}$ & & $\begin{array}{l}\text { Jelbert et } \\
\text { al. } 2014\end{array}$ \\
\hline “ & & & 8 & 6 & $\begin{array}{l}3 \text { preferred } \\
\text { water over } \\
\text { sand tube }\end{array}$ & $\begin{array}{l}6 \text { preferred } \\
\text { sinking over } \\
\text { floating objects }\end{array}$ & $\begin{array}{l}6 \text { preferred } \\
\text { solid over } \\
\text { hollow } \\
\text { objects }\end{array}$ & $\begin{array}{l}4 \text { preferred } \\
\text { narrow } \\
\text { over wide } \\
\text { tube }\end{array}$ & $\begin{array}{l}3 \\
\text { preferred } \\
\text { wide over } \\
\text { narrow } \\
\text { tube }\end{array}$ & $\begin{array}{l}1 \text { preferred } \\
\text { connected } \\
\text { apparatus } \\
\text { when } \\
\text { mechanism } \\
\text { was hidden }\end{array}$ & $\begin{array}{l}0 \text { preferred } \\
\text { connected } \\
\text { apparatus } \\
\text { when } \\
\text { mechanism } \\
\text { was exposed }\end{array}$ & $\begin{array}{l}\text { Logan et } \\
\text { al. } 2014\end{array}$ \\
\hline $\begin{array}{l}\text { Great-tailed } \\
\text { grackle } \\
\text { (Quiscalus } \\
\text { mexicanus) }\end{array}$ & $\mathrm{No}^{\mathrm{c}}$ & $\mathrm{No}^{\mathrm{c}}$ & 8 & 6 & $\begin{array}{l}4 \text { preferred } \\
\text { more } \\
\text { functional } \\
\text { heavy over } \\
\text { less }\end{array}$ & $\begin{array}{l}2 \text { switched } \\
\text { from preferring } \\
\text { heavy to no } \\
\text { preference } \\
\text { when only light }\end{array}$ & $\begin{array}{l}0 \text { preferred } \\
\text { narrow } \\
\text { over wide } \\
\text { tube }\end{array}$ & & & & & $\begin{array}{l}\text { Logan } \\
2015 a\end{array}$ \\
\hline
\end{tabular}




\begin{tabular}{lccll}
\hline Bird Species & Cacher? & $\begin{array}{c}\text { Tool } \\
\text { user? }\end{array}$ & $\begin{array}{l}\text { n stone } \\
\text { droppers }\end{array}$ & Water Tube Experiments \\
\hline & & & $\begin{array}{l}\text { functional } \\
\text { light objects }\end{array}$ & object was \\
& & & functional \\
\hline
\end{tabular}

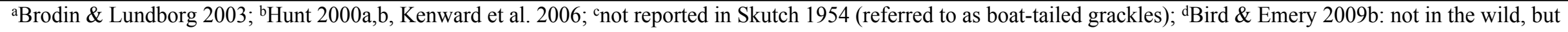

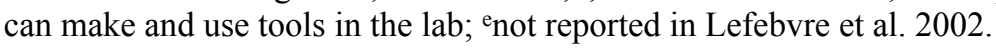




\section{Table 2 (on next page)}

All choices per trial per bird per experiment

The order in which the functional and relatively more functional choices (dark gray: water, heavy, light, rewarded color, connected), or non-functional and relatively less functional choices (light gray: sand, light, heavy, unrewarded color, unconnected) were chosen (columns) and whether the bird successfully obtained the food (marked with an X) for trials 1-20 (rows). 
Experiment 1.

Water vs. Sand

GG
Experiment 2. Heavy vs. Light GG
BB
Experiment 3. Heavy vs.
Light Magic $\quad \begin{gathered}\text { Experiment } 4 . \\ \text { Colored U-tube }\end{gathered}$

BB

\section{Experiment 5. \\ Uncovered \\ U-tube \\ BB}

\begin{tabular}{|c|c|c|c|c|c|c|c|c|c|c|c|c|c|c|c|c|c|c|c|c|c|c|c|c|c|c|c|c|c|c|c|c|c|}
\hline \multicolumn{6}{|c|}{ Insertion Order } & \multicolumn{5}{|c|}{ Insertion Order } & \multicolumn{7}{|c|}{ Insertion Order } & \multicolumn{6}{|c|}{ Insertion Order } & \multicolumn{6}{|c|}{ Insertion Order } & \multicolumn{4}{|c|}{ Insertion Order } \\
\hline Trial & 1 & 2 & 3 & 4 & Trial & 1 & 2 & 3 & 4 & 5 & Trial & 1 & 2 & 3 & 4 & 5 & Trial & 1 & 2 & 3 & 4 & 5 & 6 & Trial & 1 & 2 & 3 & 4 & Trial & 1 & 2 & 3 & 4 \\
\hline 1 & & & & & 1 & & & & & & 1 & & & & X & & 1 & & & & & & & 1 & X & & & & 1 & & X & & \\
\hline 2 & & $X$ & & & 2 & & & $\mathrm{X}$ & & & 2 & & & & X & & 2 & & $X$ & & & & & 2 & & & & & 2 & & & $\mathrm{X}$ & \\
\hline 3 & & & $\mathrm{X}$ & & 3 & & & X & & & 3 & & $X$ & & & & 3 & & $X$ & & & & & 3 & & & & $\mathrm{X}$ & 3 & & $\mathrm{X}$ & & \\
\hline 4 & $\mathrm{X}$ & & & & 4 & & & & & $\mathrm{X}$ & 4 & & & & $\mathrm{X}$ & & 4 & & & & & & & 4 & & & $\mathrm{X}$ & & 4 & & & $\mathrm{X}$ & \\
\hline 5 & $\mathrm{X}$ & & & & 5 & & & $\mathrm{X}$ & & & 5 & & & $X$ & & & 5 & $\mathrm{X}$ & & & & & & 5 & $X$ & & & & 5 & & $\mathrm{X}$ & & \\
\hline 6 & $X$ & & & & 6 & & & & & & 6 & & $X$ & & & & 6 & & & & & & & 6 & & & & $\mathrm{X}$ & 6 & X & & & \\
\hline 7 & X & & & & 7 & & & & & & 7 & & & X & & & 7 & & & & & & & 7 & & & & $X$ & 7 & & & & $\mathrm{X}$ \\
\hline 8 & & & $\mathrm{X}$ & & 8 & & & & & & 8 & & & & & $\mathrm{X}$ & 8 & & & & & & & 8 & & $\mathrm{X}$ & & & 8 & & & & $X$ \\
\hline 9 & & & & & 9 & & X & & & & 9 & & & & $\mathrm{X}$ & & 9 & & & & & & & 9 & $X$ & & & & 9 & & & $X$ & \\
\hline 10 & & & & & 10 & & & & & & 10 & & & & $X$ & & 10 & & & & & & & 10 & & & & X & 10 & $\mathrm{X}$ & & & \\
\hline 11 & & & & & 11 & & & & & & 11 & $X$ & & & & & 11 & & $\mathrm{X}$ & & & & & 11 & $X$ & & & & 11 & $\mathrm{X}$ & & & \\
\hline 12 & $X$ & & & & 12 & $\mathrm{X}$ & & & & & 12 & & & X & & & 12 & & & & & & & 12 & & & X & & 12 & & & $\mathrm{X}$ & \\
\hline 13 & & & & & 13 & X & & & & & 13 & & & & & $\mathrm{X}$ & 13 & & & & & & & 13 & & & $X$ & & 13 & $\mathrm{X}$ & & & \\
\hline 14 & & & & & 14 & & & & & & 14 & & & & & $\mathrm{X}$ & 14 & & & & & & & 14 & & X & & & 14 & & & & X \\
\hline 15 & & X & & & 15 & X & & & & & 15 & & & & $X$ & & 15 & & & $X$ & & & & 15 & & & & & 15 & & & & \\
\hline 16 & & & & & 16 & X & & & & & 16 & & & $X$ & & & 16 & $X$ & & & & & & 16 & & & & $X$ & 16 & & & $\mathrm{X}$ & \\
\hline 17 & & $\mathrm{X}$ & & & 17 & & $\mathrm{X}$ & & & & 17 & $\mathrm{X}$ & & & & & 17 & $X$ & & & & & & 17 & & $\mathrm{X}$ & & & 17 & & & & \\
\hline 18 & & X & & & 18 & & & & & & 18 & X & & & & & 18 & & & $\mathrm{X}$ & & & & 18 & $X$ & & & & 18 & & & X & \\
\hline 19 & & & $\mathrm{X}$ & & 19 & X & & & & & 19 & & & X & & & 19 & & & & & & & 19 & & X & & & 19 & X & & & \\
\hline 20 & & & & $\mathrm{X}$ & 20 & & & $\mathrm{X}$ & & & 20 & & & & & $\mathrm{X}$ & 20 & & & $\mathrm{X}$ & & & & 20 & & $\mathrm{X}$ & & & 20 & & & & \\
\hline
\end{tabular}




\section{Table 3 (on next page)}

Summary of results

The number of trials required to learn to associate food with the gold tube (color learning; min. 17 out of 20 trials correct) and to become proficient at dropping stones down the platform apparatus (stone drop training; number of non-proficient stone falls plus 30 proficient stone drops); total number of correct choices / total number of choices and pvalues from binomial tests for experiments 1-5 (the Bonferroni-Holm correction was applied to Experiment 2). $\mathrm{X}=$ bird did not complete this experiment, - = bird did not participate in this experiment. 


\begin{tabular}{|c|c|c|c|c|c|c|c|c|}
\hline Bird ID & Sex & $\begin{array}{l}\text { Color } \\
\text { Test }\end{array}$ & $\begin{array}{l}\text { Stone Drop } \\
\text { Training }\end{array}$ & $\begin{array}{l}\text { Exp 1: } \\
\text { Water vs. } \\
\text { Sand }\end{array}$ & $\begin{array}{l}\text { Exp 2: } \\
\text { Heavy vs. } \\
\text { Light }\end{array}$ & $\begin{array}{l}\text { Exp 3: Heavy } \\
\text { vs. Light } \\
\text { Magic }\end{array}$ & $\begin{array}{l}\text { Exp 4: } \\
\text { Colored } \\
\text { U-tube }\end{array}$ & $\begin{array}{l}\text { Exp 5: } \\
\text { Uncovered } \\
\text { U-tube }\end{array}$ \\
\hline BB & $\mathrm{F}$ & 80 & 76 & $X$ & $\begin{array}{c}33 / 56 \\
0.46\end{array}$ & $\begin{array}{c}42 / 68 \\
0.06\end{array}$ & $\begin{array}{c}30 / 52 \\
0.33\end{array}$ & $\begin{array}{c}32 / 53 \\
0.17\end{array}$ \\
\hline GG & $\mathrm{M}$ & $X(28)$ & 255 & $\begin{array}{c}29 / 51 \\
0.40\end{array}$ & $\begin{array}{c}27 / 45 \\
0.46\end{array}$ & - & - & - \\
\hline $\mathrm{H}$ & $\mathrm{M}$ & 20 & $X(507)$ & - & - & - & - & - \\
\hline PA & $\mathrm{M}$ & 50 & $X(536)$ & - & - & - & - & - \\
\hline
\end{tabular}

1 